\title{
Aristóteles y Tomás de Aquino: un análisis en torno a la polis y la res publica
}

Juan David Almeyda Sarmiento

Universidad Industrial de Santander, Colombia 


\title{
Aristóteles y Tomás de Aquino: un análisis en torno a la polis y la res publica*
}

Resumen: el presente trabajo analiza la relación existente entre los conceptos polis y res publica. El primer concepto desarrollado por Aristóteles en sus obras Ética Nicomáquea y Política; el segundo, expuesto por Tomás de Aquino en Comentario a la Ética de Aristóteles, Comentario a la política de Aristóteles y La monarquía, al rey de Chipre. El objetivo de este artículo es responder a la pregunta $i$ cuáles son las diferencias y similitudes entre el concepto de polis en Aristóteles y el de res publica en Tomás de Aquino? Para dar respuesta a este planteamiento se estructuran tres acápites: inicialmente, se profundiza en el concepto de polis; luego, se ahonda en la res publica tomista y, finalmente, se presentan los puntos en común y las diferencias entre ambos términos.

Palabras clave: polis, res publica, Aristóteles, Tomás de Aquino, historia de la filosofía.

\section{Aristotle and Thomas Aquinas: an analysis \\ around the polis and the res publica}

\begin{abstract}
: this paper analyzes the relationship between the concepts polis and res publica. The first concept developed by Aristotle in his works Nicomachean Ethics and Politics; the second, exposed by Thomas Aquinas in Commentary on the Ethics of Aristotle, Commentary on the politics of Aristotle and The monarchy, to the king of Cyprus. The objective of this article is to answer the question: what are the differences and similarities between the concept polis in Aristotle and the concept of res publica in Thomas Aquinas? To respond to this approach, three sections are structured: initially, the concept of polis is deepened; then, it delves into the thomist res publica and, finally, the points in common and their differences between both terms are presented.
\end{abstract}

Keywords: polis, res publica, Aristotle, Thomas Aquinas, History of philosophy.

Fecha de recepción: 1 de febrero de 2019

Fecha de aceptación: 3 de julio de 2019

Forma de citar (APA): Almeyda-Sarmiento, J. (2020). Aristóteles y Tomás de Aquino: un análisis en torno a la polis y la res publica. Revista Filosofía UIS, 19(1), DOI: 10.18273/revfil. v19n1-2020011

Forma de citar (Harvard): Almeyda-Sarmiento, J. (2020). Aristóteles y Tomás de Aquino: un análisis en torno a la polis y la res publica. Revista Filosofía UIS, 19(1), 35-58.

Juan David Almeyda Sarmiento: colombiano. Profesional en Filosofía de la Universidad Industrial de Santander, Colombia.

ORCID iD: orcid.org/0000-0002-6463-6388

Correo electrónico: juanalmeyda96@gmail.com; juan.almeyda1@correo.uis.edu.co

"Artículo de reflexión derivado de investigación. 


\section{Aristóteles y Tomás de Aquino: un análisis en torno a la polis y la res publica'}

\section{Introducción}

Este artículo presenta los conceptos de polis y res publica, pertenecientes a Aristóteles y a Tomás de Aquino respectivamente, de modo que sea posible establecer puntos de encuentro y diferencia entre ambos. Cada apartado presenta tres partes donde se plantean distintas lecturas del concepto a trabajar para poder abarcar una interpretación con la rigurosidad que se debe. La primera parte, expone la manera en la que el concepto correspondiente era entendido en el contexto del autor, exponiendo ideas generales de investigadores especializados; la segunda parte presenta el concepto en las obras correspondientes de cada autor, este momento tiene en cuenta la bibliografía principal de los filósofos para dar una interpretación a partir de la lectura del concepto a tratar; finalmente, el último presenta una lectura ampliada de los conceptos de los autores desde la mirada de la bibliografía secundaria, de modo que sea posible ampliar el estudio conceptual.

Con lo anterior, la estructura de este trabajo se divide en tres partes: el primero se dedica exclusivamente al concepto aristotélico de polis, es decir, busca exponer la manera en la cual este pensador de la Grecia Antigua, en sus dos obras principales sobre la comunidad de los hombres (Ética Nicomáquea y Política), articula todo su pensamiento en lo que corresponde a la organización de la sociedad. Así, se busca exponer la manera en la cual la reunión de los seres humanos debe ser llevada a cabo en la práctica, de modo que sea posible una vida feliz en la cual el ciudadano tenga plenitud y una vida acorde a las disposiciones con las cuales cuenta en calidad de zoon politikon.

El segundo apartado refiere a Tomás de Aquino y su res publica. En este momento se expone que Marco Tulio Cicerón y Agustín de Hipona son dos pensadores que influenciaron la manera desde la cual Aquino pensó su idea

${ }^{1}$ El presente artículo es resultado del proceso de investigación llevado a cabo durante mi trabajo de grado en filosofía en la Universidad Industrial de Santander, tesis que fue dirigida por el Prof. Dr. Dr. Andrés Botero Bernal. 
de res publica. Además, se presenta a Tomás como un filósofo que sintetizó el pensamiento que lo precedía para articular su propia manera de pensar el contexto histórico y aportar, por medio de la filosofía y la teología fundamentada en el cristianismo, a la solución de los problemas de su época.

En el tercer apartado, se exponen ambos conceptos a un análisis por medio del cual sea posible dilucidar las similitudes y diferencias que se presentan a la hora de pensar ambos términos. En este punto de la investigación se concluyen los distintos matices que existen entre ambos conceptos y la razón de ser de dichas distancias conceptuales, además, se trae a colación la manera en la cual se puede pensar la filosofía política tomista, en lo que respecta a la dimensión social y política que corresponde al reflexionar sobre la comunidad, como una continuidad y una expansión de lo escrito por Aristóteles.

\section{La noción de polis en la Grecia clásica y en Aristóteles}

Preguntar por la noción de polis, sus implicaciones y la variedad de interpretaciones, requiere pensar cómo el griego de la Grecia clásica (500-313 a. C.) se relacionaba con su organización social y política en orden de desempeñar un rol en esta comunidad. En una delimitación inmediata de este concepto se puede decir que:

La propia traducción del concepto de polis por «ciudad estado» pretende reflejar el hecho de que todas las polis se gobernaban a sí mismas y contaban con sus propias leyes, ejércitos (formados por los ciudadanos) y procedimientos de toma de decisión. Los arreos, por tanto, eran los propios de un estado sencillo. Pero en todos los casos, salvando solo el de Atenas, la polis era ante todo una comunidad, y el sentimiento comunitario era cuando menos tan fuerte, o quizá más aún, que los componentes del aparato estatal (Thomas, 2002, p. 85).

Esta traducción del termino polis como "ciudad-Estado" puede tener ciertas limitaciones en lo referente a la carga semántica que traía para el griego de la época. La polis no solo se entiende como la manifestación física de una serie de casas habitadas por familias; ahora bien, la anterior forma de entender la polis, de forma tan primaria e inmediata, como una somera reunión de casas y gente reduce este concepto a lo que es su verdadero potencial: ser la estructuración de la idea de organización política y social de una comunidad. Por este motivo, es necesario indagar un poco más para poder construir de forma profunda, amplia y concreta la noción de polis y su posterior interpretación desde Aristóteles; es pertinente resaltar el comentario de Julián Gallego respecto de esta traducción de la noción de polis fundamentado en los estudios realizados por la Copenhagen Polis Centre (CPC): 
Lo que los griegos veían o definían como una pólis, para luego concluir a partir de las investigaciones realizadas que, en más del 90\% de los casos en que el término pólis es utilizado en las fuentes para referirse a las comunidades de las épocas arcaica y clásica, es decir, entre los siglos VIII y IV a. C., cada vez que se utiliza el vocablo pólis se alude tanto al centro urbano principal como a la comunidad políticamente organizada, lo cual es decodificado por Mogens Hansen, como la referencia a una ciudad y a un estado, reponiendo de este modo este par característico que se ve aparecer por doquier para referirse a la pólis (Gallego, 2016, p. 2).

En este proceso de investigación de la polis dice Morgens Hansen, director del Copenhagen Polis Centre, unidad investigativa de la Universidad de Copenhague que durante los últimos tres lustros ${ }^{2}$, se ha dedicado a analizar este concepto de la polis:

Los griegos sabían muy bien que usaban la palabra polis con más de un significado, y las fuentes muestran que en los períodos Arcaico y Clásico la palabra tenía dos sentidos principales: (1) pobladores y (2) comunidad. Como asentamiento, una polis consistía en casas; como comunidad consistía en personas: una es un sentido físico concreto, la otra más abstracta y personal. Además, las fuentes muestran que no todos los asentamientos o comunidades eran polis. Como asentamiento, una polis era principalmente un gran asentamiento nucleado, es decir, una ciudad; como comunidad, era una comunidad política institucionalizada, dicho de otro modo, un estado (Hansen, 2006, p. 56) ${ }^{3}$.

Continuando con lo anterior, el proceso de definir la noción de polis para la Grecia clásica requiere profundizar las dos nociones expuestas por los estudios de Hansen: la polis como una comunidad política, de un lado, y como un centro urbano, del otro. En estos dos significados, los cuales se unen y funcionan de forma conjunta de manera semántica ${ }^{4}$, se despliega toda la noción de lo que para el hombre griego de la época clásica era su manera de interactuar con su organización social:

En ese sentido, polis pudo llegar a designar el centro urbano por derivación del hecho de que ese conjunto se aglutinaba en torno a una ciudadela que, en principio, podía haber servido de refugio a los que integraban esa comunidad. Pero, así como está consignado el vocablo polis con el sentido de centro urbano en el que se habita, así también [...] polis designa una comunidad política, esto es, un Estado (Gallego, 2006, pp. 161-162).

\footnotetext{
${ }^{2}$ Véase Gallego, 2006, p. 157.

${ }^{3}$ Toda referencia que no se encuentre en castellano es traducción propia.

${ }^{4}$ Véase Gallego, 1996.
} 
Ahora bien, los estudios de Hansen permiten dilucidar la relación entre los dos significados predominantes de la noción de polis. No son solamente sus partes físicas, por un lado, y su comunidad política o Estado por el otro, es una noción que el griego de la Época Clásica fundía de forma conjunta y que le permitía entenderse en su vida política y social.

Sentado lo anterior, se analiza la noción de polis que expone Aristóteles. El estagirita elabora una noción que busca responder a la forma como era concebida la polis en su época para, posteriormente, exponer su propia forma de entenderla. Inicialmente, se expone en el libro I de Política: "La comunidad perfecta de varias aldeas es la ciudad [...] que nació a causa de las necesidades de la vida, pero subsiste para el vivir bien. De aquí que toda ciudad es por naturaleza" (Aristóteles, Política, I, 1252b8). Aristóteles expone, a nivel general, qué entiende por polis. Una noción que utiliza para fundamentar lo que es su idea del hombre como un animal social: "la ciudad es una de las cosas naturales, que el hombre es por naturaleza un animal social, y que el insocial por naturaleza y no por azar es o un ser inferior o un ser superior al hombre" (Aristóteles, Política, I, 1253a9).

Una vez expuesta la caracterización del individuo que habita la polis, el animal social (zoon politikón): "Quizá es también absurdo hacer del hombre dichoso un solitario, porque nadie, poseyendo todas las cosas, preferiría vivir solo, ya que el hombre es un ser social y dispuesto por la naturaleza a vivir con otros" (Aristóteles, Ética Nicomáquea, IX, 1169b15), Aristóteles recurre a su forma de hacer ciencia para explicar las demás partes que componen el todo, en este caso, las partes que componen la totalidad que es la polis: la casa (oikía) (Aristóteles, Política, I, 1253b7-11), una unidad familiar constituida por padre, madre, hijos, esclavos y bien material: "Por naturaleza, pues, la ciudad es anterior a la casa y a cada uno de nosotros, porque el todo es necesariamente anterior a la parte" (Aristóteles, Política, I, 1253a13). Esta forma de entender la polis, como un todo constituido por individuos que son sus partes, es la base del planteamiento éticopolítico que se puede apreciar en la propuesta aristotélica de polis (Aristóteles, Ética Nicomáquea, VIII, 1160a10-30), propuesta que se puede observar en los inicios del libro II, en la cual expone el segundo componente de la polis, la pluralidad de hombres en relación con sus oficios:

Es evidente que al avanzar en este sentido y hacerse más unitaria, ya no será ciudad. Pues la ciudad es por su naturaleza una cierta pluralidad, y al hacerse más una, de ciudad se convertirá en casa, y de casa en hombre, ya que podríamos afirmar que la casa es más unitaria que la ciudad y el individuo más que la casa. De modo que, aunque alguien fuera capaz de hacer esto, no debería hacerlo, porque destruiría la ciudad. 
Y no sólo la ciudad está compuesta de una pluralidad de hombres, sino que también difieren de modo específica. Una ciudad no resulta de individuos semejantes. Una cosa es una alianza militar y otra una ciudad (Aristóteles, Política, II, 1261a2-3).

Esta idea de la pluralidad en la polis es resultado de la variedad de hombres que se encuentran en la polis y se conjuga con la importancia que Aristóteles da a la amistad, como principio de sociabilidad entre hombres miembros de una misma polis: "la tarea de la política consiste, sobre todo, según parece, en promover la amistad; y, por eso, se dice que la virtud es útil, pues es imposible que sean amigos entre sí los que son recíprocamente injustos" (Aristóteles, Ética Eudemia, VII, 1234b25). La amistad se torna fundamental en cuanto virtud del hombre que vive con otros diferentes a él: "En efecto, sin amigos nadie querría vivir, aunque tuviera todos los otros bienes; incluso los que poseen riquezas, autoridad o poder parece que necesitan sobre todo amigos" (Aristóteles, Ética Nicomáquea, I, 1155a5).

El ciudadano es, entonces, aquel que participa de las magistraturas, además el concepto de ciudadano se somete al tipo de régimen pues, dice Aristóteles, de acuerdo con el tipo de régimen puede uno ser o dejar de ser ciudadano (Aristóteles, Ética Nicomáquea, VIII, 1161a30-1161b10). Lo anterior, de acuerdo a si el carácter de dicha forma de gobierno es recto o desviado; así, en una cierta definición común de lo que es el ciudadano; en otros términos, el estagirita encuentra algo que subyace en la manera de entender al ciudadano que concuerda sin importar el régimen al cual pertenezca, Aristóteles escribe: "a quien tiene la posibilidad de participar en la función deliberativa o judicial, a ese llamamos ciudadano de esa ciudad; y llamamos ciudad, por decirlo brevemente, al conjunto de tales ciudadanos suficiente para vivir con autarquía" (Aristóteles, Política, III, 1275b12).

A continuación, se trabaja el siguiente elemento constitutivo de la polis: las formas de gobierno. Esta cuarta parte tiene la cualidad de afectar ciertas características de las otras nociones como lo son las de ciudadano y ciudad en la medida en que cada régimen responde a ciertas características específicas en su forma de ejercer el orden en la ciudad (Aristóteles, Ética Nicomáquea, I, 1094b5); así, Aristóteles fundamenta que alguna forma de gobierno debe existir para alcanzar la finalidad de la polis: el vivir bien, una condición más allá del mero habitar y existir en una comunidad, para lo cual se requiere del desarrollo de la virtud. Es decir, la ciudad se forma por naturaleza con el fin de las buenas acciones y no por la mera convivencia (Aristóteles, Ética Nicomáquea, VII, 1157a25).

Ahora bien, los regímenes son divididos por el estagirita en seis: monarquía, aristocracia y politeia, como regímenes rectos; y tiranía, oligarquía y democracia, 
como desviados (Platón, Las Leyes, IV, 709e-713a), (Platón, Las Leyes, VIII, 823bd $)^{5}$. Sobre cada forma expone sus virtudes y desventajas, inclinado Aristóteles a la politeia, para concluir con la importancia de las formas de gobierno en la comunidad política, lo cual funciona como fundamento para sustentar su proyecto ético-político que se da únicamente en la vida en sociedad:

Éste es, efectivamente, el fin principal, tanto de todos en común como aisladamente. Pero también se reúnen por el mero vivir, y constituyen la comunidad política. Pues quizá en el mero hecho de vivir hay una cierta parte del bien, si en la vida no predominan en exceso las penalidades. Es evidente que la mayoría de los hombres soportan muchos sufrimientos por su vivo deseo de vivir, como si en el vivir hubiera una cierta felicidad y dulzura natural (Aristóteles, Política, III, 1278b4).

Finalmente, en el libro VII, Aristóteles expone su pensamiento en torno al Estado ideal, donde formula los que son para él los parámetros y las condiciones para una polis perfecta, ideas respecto al Estado que permitirán el desarrollo pleno de las virtudes de los ciudadanos para alcanzar la felicidad.

Existe gran variedad de estudios sobre la organización de la sociedad que se encuentra presente en los textos aristotélicos, en la mayoría de estas investigaciones especializadas se puede encontrar una lectura detallada de la noción de polis que el estagirita componía en sus textos: "En la Política de Aristóteles se aborda de manera conceptual el vínculo entre el orden social ideal y su espacio asociado [...] el filósofo no solo intenta describir la polis griega ideal, sino definir una teoría general de las constituciones" (Llanos, 2013, p. 25).

La construcción del aparato social desde la mirada de Aristóteles toma un fuerte vínculo con lo ético para fundamentar la finalidad del animal social: "La conclusión [...] es entender la polis como una comunidad que se auto-organiza para lograr el bien común, ideal que siempre está sobre los individuos y es independiente de las características formales del espacio en que se desarrolle la comunidad" (Goycoolea, 2005, p. 6).

Michael Sakellariou, siguiendo la tarea de enriquecer la multiplicidad de sentidos que existen en la palabra polis, intenta presentar una aproximación de las distintas connotaciones que Aristóteles da al término polis en Política: "(i)ró

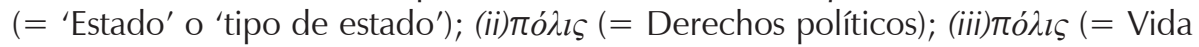

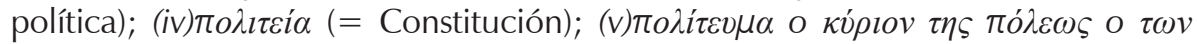

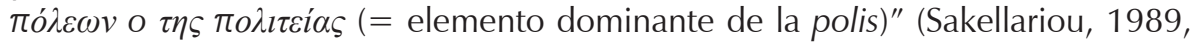
p. 288).

\footnotetext{
${ }^{5}$ Debe tenerse en cuenta que Aristóteles toma este análisis sobre los regímenes políticos de su maestro Platón. En Política se encuentran estos regímenes explicados, pero realmente la descripción del estagirita viene derivada directamente del trabajo realizado por Platón en Las Leyes. Sobre esto ver el pie de página de la traducción de Política, de la editorial Gredos (cfr. García, 1998, p. 171).
} 
Así, Sakellariou, no reduce la polis a una mera noción de ciudad-Estado. Este autor únicamente comparte la manera en que el concepto se fusiona y transforma de acuerdo con el contexto, pero la esencia última y unificadora se mantiene siempre en la noción de comunidad política compuesta por una serie de elementos constitutivos sin los cuales dicha comunidad no puede existir.

Ahora bien, al partir del análisis de Sakellariou, es necesario pensar estos dos grupos a los que pertenece la noción aristotélica de polis. Este comentarista delimita, a lo largo de todo su análisis del concepto, una variedad de sentidos que permiten dilucidar que la polis no es poseedora de una única forma de ser entendida, sino que es propio de este concepto la multiplicidad de otros términos para encontrar su forma completa. Sakellariou construye un delicado y detallado análisis de los usos que Aristóteles da el concepto, sin que estos usos sean contrarios entre sí; es decir, su multiplicidad no deriva en contradicciones a la hora de pensar la polis. Lo anterior, debido a que cada una de las distintas maneras en que se recurre al concepto, para Sakellariou, siempre son tomados del contexto del estagirita, lo cual permite entender esta forma de delimitar la polis como una suma lógica de cada uno de estos significados individuales; teniendo estos últimos su veracidad para ser utilizados en la medida en que el estagirita los emplea en sus textos de acuerdo a un contexto especifico. Esto es, la única forma de pensar la polis es por medio de la multiplicidad intrínseca que para Aristóteles este concepto posee.

A partir de lo anterior, la polis aristotélica se expone como un fenómeno natural propio del hombre, un fenómeno que envuelve al ser humano, en cuanto que zoon politikón, llevándolo a encontrar, desde su naturaleza, la plenitud. En este sentido, el orden al cual da correspondencia Aristóteles es: familia, aldea y, posteriormente, polis. Por tanto, la polis responde a un proceso de evolución que permite mejorar poco a poco la forma en la cual los individuos, que conforman esta comunidad humana, Ilegan a buscar una finalidad más profunda que las meras necesidades básicas, tal y como lo expone David Reeve:

Las necesidades humanas bastante básicas hacen lo primero, pero lo que sostiene una polis en existencia es que podemos vivir bien y alcanzar la felicidad solo en ella. Así, la polis es autosuficiente no solo porque satisface necesidades esenciales, sino porque es la comunidad dentro de la cual perfeccionamos o realizamos nuestras naturalezas o funciones. El hogar, el pueblo y la polis son como embriones, niños y adultos maduros: una naturaleza única está presente en cada etapa pero desarrollada o completada en diferentes grados (2009, p. 516).

Bajo esta búsqueda de superar las necesidades básicas es que el ser humano se posiciona de forma superior a las abejas, las hormigas, y demás creaturas de la naturaleza que, al igual que el hombre, tienen la misma cualidad de juntarse y 
formar comunidades. La superación de las otras formas de comunidad humana por una más completa que permita al ser humano alcanzar todo su potencial radica en su naturaleza pues, al ser un zoon politikon, las facultades de las cuales esta condición le dispone dan paso a pensar la comunidad como un espacio donde se permita el acceso a un crecimiento conjunto donde la felicidad derivada de la virtud lleve al ser humano a alcanzar su compleción en calidad de hombre.

Analizar la forma en que procede la polis aristotélica desde lo primitivo y básico de la familia a lo completo y articulado de la polis abre espacio a pensar la manera en que este tipo de comunidad que define Aristóteles es una multiplicidad que se ve unida a un bien común como lo es la felicidad. Es por esto que los procesos de síntesis, que se ven evidenciados en el proceso que por naturaleza lleva al hombre a completarse a sí mismo, son una característica ético-política propia del futuro ciudadano de la polis. Se hace referencia a futuro ciudadano en la medida que inicialmente este último existe como miembro de una familia mas no como ciudadano, se debe tener en cuenta que la disposición del ser humano a su potencial, el cual se da por naturaleza, hace que la relación entre los hombres de igual forma se desarrolle a manera de síntesis. Todo esto lleva a concluir la razón de ser de la polis, puesto que los distintos elementos que la componen, como la Constitución, el régimen, las instituciones públicas, y demás, son derivados de la propia naturaleza del hombre en su búsqueda por llegar a la plenitud propia del zoon politikon, sobre esto expone Enrico Berti: "La definición aristotélica de polis está más cerca de la definición hegeliana de «Estado político», que indica un «todo», un entero, una totalidad. Por algo Hegel tradujo el griego polis con Staat" (Berti, 2012, p. 23).

Las reflexiones de Berti, al igual que las de Reeve y los demás autores citados, sustentan la manera de proceder del ser humano en lo que respecta a la polis como una comunidad ético-política que existe como una síntesis de otras formas menores de comunidad que no llevan a cumplir con la naturaleza del hombre en su totalidad sino meramente suplen con las necesidades básicas que nacen en el día a día.

\section{La noción de res publica en el Medievo y en Tomás de Aquino}

La baja Edad Media (1050 d. C.-1290 d. C.) es el contexto histórico en el cual el pensamiento de Tomás de Aquino se desarrolla. Ahora bien, para iniciar la reflexión de las nociones políticas del aquinate es requisito, primero, pensar cómo el pensamiento político romano, centrado especialmente en las perspectivas políticas de Marco Tulio Cicerón, marcó la pauta para el desenvolvimiento del concepto de res publica. Este autor romano permite pensar las bases teóricas del 
pensamiento político que prosiguió de él ${ }^{6}$, como expone Louise Hodgson sobre este elemento propio de la vida política en comunidad:

Res publica no se refiere a 'la' o incluso 'una' comunidad, excepto en la medida en que una res publica pertenece a una comunidad y es administrada por una subsección altamente politizada de esa comunidad que puede confundirse mucho sobre la diferencia entre sus intereses y los de los asuntos cívicos confiados a su administración por el bien común. Esto presagia la razón por la cual [...] leer res publica literalmente como "lo público" a menudo puede ser engañoso y por lo general debe evitarse: diferentes partes de la misma comunidad tendrán diferentes perspectivas sobre su res publica compartida (Hodsong, 2017, pp. 4-5).

Ahora bien, para entrar en el estudio de la noción de res publica, Cicerón y Agustín de Hipona son los autores que más influyen en la línea de pensamiento de Tomás Aquino para la construcción de su propia noción de res publica ${ }^{7}$. En ese orden de ideas, inicialmente se expone la forma de entender este concepto por parte de Cicerón:

Así pues, la cosa pública (república) es lo que pertenece al pueblo; pero pueblo no es todo conjunto de hombres reunido de cualquier manera, sino el conjunto de una multitud asociada por un mismo derecho que sirve a todos por igual. La causa originaria de esa conjunción no es tanto la indigencia humana cuanto cierta como tendencia asociativa natural de los hombres, pues el género humano no es de individuos solitarios (Cicerón, Sobre la república, I, 25, 39 y 26, 41).

Es preciso aclarar algunas nociones básicas de lo que puede significar el concepto "cosa". Lo primero a denotar es que en la obra de Cicerón no hay nada que explique qué entiende por cosa. Antes bien, se puede decir que, en el contexto de la cultura latina, cosa puede ser entendida, por un lado, como un objeto y, por el otro, como un cierto ejercicio ${ }^{8}$. De nuevo con el análisis de la res publica y la ciudad, Cicerón construye una noción de res publica donde da las características intrínsecas necesarias para la existencia de esta organización social y política como es la necesidad de derecho y justicia dentro de una finalidad moral.

Sentado lo anterior, Agustín de Hipona toma un papel importante en la constitución del pensamiento político con respecto a la organización social, en

$\overline{{ }^{6} \text { Véase Sellers, } 2009 .}$

${ }^{7}$ Véase Woldring, 1999

${ }^{8}$ Véase Sánchez, 2016. 
especial su crítica a la noción de res publica ciceroniana: "Gracias al giro que Agustín da a la definición ciceroniana de república, solo la Ciudad de Dios puede denominarse como tal, pues únicamente ella cumple cabalmente con las exigencias que debe satisfacer una colectividad para considerarse república" (Sánchez, 2016, p. 228).

Agustín de Hipona encuentra en el amor el fundamento de la unión y la convivencia entre hombres (La ciudad de Dios, XIV, 28), de ahí que construye una crítica a las nociones ciceronianas, pues no considera como ciudad digna de ser habitada por hombres a la simple agrupación de gente: "Cuando el hombre no se somete a Dios iqué justicia queda en él?, si el alma no está sometida a Dios, por ningún derecho puede ella dominar el cuerpo ni la razón ni los vicios" (La ciudad de Dios, XIX, 24). Este fundamento metafísico del amor constituye para él una prioridad en la verdadera res publica, por ello la concordia solo se da en el sometimiento y la aceptación de Dios y la fe en las cuestiones de la res publica.

De esta forma, Agustín de Hipona constituye una teoría política respecto a la manera en que debe de entenderse la relación entre la sociedad y la religión, más específicamente el discurso religioso basado en la teología cristiana, para proceder de forma armoniosa con las monarquías existentes que buscaban mantener su soberanía por encima de la ley de la Iglesia. El aquinate buscaba que la ley divina (lex aeterna) fuera la principal fuente de inspiración para aquel que se encarga de la legislación y de este modo el orden social y político de la comunidad estuviera orientado y fundamentado bajo la ética que resguarda los principios cristianos hacia Dios.

Tomás de Aquino desarrolla en Comentario a la Política de Aristóteles y Comentario a la Ética de Aristóteles una clara identidad e influencia por el pensamiento político aristotélico. Su forma de hacer filosofía y teología se sustenta en las ideas del estagirita y esto lo evidencia a lo largo de ambos comentarios, y en este caso la organización social es la noción aristotélica que toma y plantea para su posterior aplicación en su propia época como se ve en La monarquía, al rey de Chipre.

Tomás de Aquino inicia su Comentario a la Política diciendo: "La ciudad es lo principal en lo que puede referirse a las comunidades humanas. Además, en las artes mecánicas, los todos constituidos por las cosas que llegan al uso del hombre se ordenan a este como a su fin" (Pol., I, pref.). Esto lo escribe en el prólogo al Comentario, donde expone conclusiones iniciales de Aristóteles bajo su propia perspectiva: "En esas comunidades, [...] la última es la comunidad de la ciudad, ordenada por suficiencia por sí de la vida humana. De ahí que entre todas las comunidades humanas la ciudad es la más perfecta" (Pol., I, pref.). 
El proceder tomista lleva a comentar parte por parte del texto de Aristóteles para explicar la manera en que el estagirita construye su pensar ético-político: "toda comunidad está constituida por algún bien, pero toda ciudad, como se verá, es una comunidad, luego toda ciudad es instituida por algún bien" (Pol., I, 1). Tomás de Aquino trabaja uno a uno, de la misma forma que Aristóteles, los componentes que constituyen la ciudad (en cuanto que cuerpo sociopolítico); esta vez, claro está, no como la polis de Aristóteles, sino que fundamenta su res publica bajo la influencia agustiniana de la crítica a Cicerón, sin dejar de lado el pensamiento ciceroniano: "la comunidad perfecta será la que se ordene a que el hombre posea con suficiencia lo necesario para vivir, tal comunidad es la ciudad" (Pol., I, 1).

Todo este estudio por parte de Tomás de Aquino respecto al pensamiento ético-político de Aristóteles en sus comentarios luego se ve reflejado en La monarquía, al rey de Chipre, donde expone la filosofía aristotélica bajo su propia línea de pensamiento:

El hombre tiene algún fin al que se ordena toda su vida y su acción [...] pero resulta que el hombre se dirige a tal fin de modos diversos, cosa que la misma diversidad de las inclinaciones y acciones humanas nos muestra, luego el hombre necesita alguien que lo dirija a su fin [...] Y si en verdad le conviniera al hombre vivir individualmente [...] no necesitaría de nadie que lo dirigiera a su fin [...] pero corresponde a la naturaleza del hombre ser un animal sociable y político que vive en sociedad, más aún que el resto de los animales, cosa que nos revela su misma necesidad natural [...] porque un solo hombre por sí mismo no puede bastarse en su existencia. Luego el hombre tiene como natural el vivir en una sociedad de muchos miembros (Tomás de Aquino, La monarquía, al rey de Chipre, pp. 673-674).

Para el aquinate, el pensamiento aristotélico constituye una fuente de inspiración que, en conjugación con la Ley divina y las virtudes cristianas, las personas tienen el deber de seguir para conseguir la plenitud de estar en el goce de Dios:

si la ley se estatuye rectamente con relación a estos fines se dice que es una ley recta. De las demás que son leyes sin examen [...] o sin reflexión o schedos, dictamen improvisado [...] por eso puede llamarse ley sin previsión (o aposchediasmenos), que carece de la debida providencia (Eth., V, 2).

Esta fuerte influencia viene derivada de las traducciones al latín de los textos Política y Ética, los cuales sirvieron de base para el trabajo de estudio y comentario a ambos textos. Tomás de Aquino presenta su noción de res publica en pocos documentos, sin embargo, se puede encontrar la forma en la que expone este 
concepto, y al hacerlo evidencia el fuerte impacto que el pensamiento éticopolítico de Aristóteles genera en su proceder teórico, ejemplo de esto es la exposición que hace el aquinate del mejor régimen:

Hay que decir: Para la buena constitución del poder supremo en una ciudad o nación es preciso mirar a dos cosas: la primera, que todos tengan alguna parte en el ejercicio del poder, pues por ahí se logra mejor la paz del pueblo, y que todos amen esa constitución y la guarden, como se dice en II Polit. La segunda mira a la especie de régimen y a la forma constitucional del poder supremo. De la cual enumera el Filósofo, en III Polit., varias especies; pero las principales son la monarquía, en la cual es uno el depositario del poder, y la aristocracia, en la que son algunos pocos.

La mejor constitución en una ciudad o nación es aquella en que uno es el depositario del poder y tiene la presidencia sobre todos, de tal suerte que algunos participen de ese poder $y$, sin embargo, ese poder sea de todos, en cuanto que todos pueden ser elegidos y todos toman parte en la elección. Tal es la buena constitución política, en la que se juntan la monarquía — por cuanto es uno el que preside a toda la nación-, la aristocracia - porque son muchos los que participan en el ejercicio del poder- y la democracia, que es el poder del pueblo, por cuanto estos que ejercen el poder pueden ser elegidos del pueblo y es el pueblo quien los elige. Tal fue la constitución establecida por la ley divina (Sum., I-II, q. 105, a. 1).

El trabajo alrededor de los elementos que constituyen la res pública representa para Tomás de Aquino un trabajo de constante conciencia de la ley superior a la cual el hombre, en virtud de creación divina, siempre debe de tener como referente a la hora de proceder en los asuntos humanos. Es decir, para el aquinate articular la vida espiritual cristiana con los asuntos humanos mundanos es un requisito que debe reflejarse en la dimensión política, ética y social de la res publica que sea digna de llamarse de esta forma:

Ahora bien, el hombre se halla colocado entre las cosas de este mundo y los bienes espirituales, en los que consiste la eterna bienaventuranza, de tal modo que cuanto más se adhiera a uno de ellos, tanto más se aparta del otro, y recíprocamente. Por lo tanto, el que totalmente se apega y adhiere a las cosas de este mundo, poniendo en ellas su fin y teniéndolas como normas y reglas de sus obras, se aparta del todo de los bienes espirituales. Tal desorden se rectifica mediante los mandamientos (Sum., I-II, q. 108, a. 4).

La noción de res publica se presenta, desde Tomás de Aquino, como parte de las cosas del mundo: "El hombre es asistido por la sociedad política, de la cual es parte no sólo con relación a lo corporal [...] sino también en relación con las morales" (Eth., I, 1). Así todo, fuera de tener un carácter anodino por su cualidad terrenal, él es consciente de la importante trascendencia que juega la organización ético-política y social que se entreteje en los distintos escalones de la jerarquía 
que se produce en el ordenamiento de las personas en una comunidad y, en esta medida, encuentra que el disponer de los distintos elementos que estructuran la res publica permite que la Providencia divina sea una posibilidad para todos en su goce sagrado:

Hay que hacer la consideración previa de que gobernar consiste en conducir lo que es gobernado a su debido fin. Así, se dice que una nave es gobernada mientras es conducida ilesa al puerto, mediante la pericia del piloto por un itinerario normal. Luego si algo se ve ordenado a un fin exterior a sí mismo, como la nave al puerto, corresponderá a la tarea del gobierno no solamente conservar la cosa ilesa, sino incluso conducirla después hasta su fin. Si por el contrario hubiese algo cuyo fin no estuviera fuera de ello mismo, la tarea del gobernador consistiría únicamente en conservar aquella cosa ilesa y perfecta (Tomás de Aquino, La monarquía, pp. 69-70).

Con la anterior cita, el aquinate expone en una metáfora su línea de pensamiento en relación a la res publica, la cual no está exenta de la teoría éticopolítica aristotélica ni de la disposición aristotélica del mundo que compone la comunidad política, que le permite llegar a la misma conclusión que el estagirita: "parece, pues, que el fin último de la multitud reunida en sociedad consiste en vivir virtuosamente [...] la vida correcta es, pues, la que se lleva según la virtud, luego la vida virtuosa constituye el fin de la sociedad humana" (Tomás de Aquino, La monarquía, p. 71). La visión de mundo tomista permite situar el régimen divino con todo lo que corresponde de acuerdo con la visión cristiana de mundo, la cual se fundamenta en las sagradas escrituras como el modelo a corresponder que debe siempre ser seguido en la estructuración de costumbres, formas de vida y de existencia.

Estudios respecto a esta noción de organización social en Tomás de Aquino pueden ayudar a dilucidar cómo entender esta noción de orden y comunidad ético-política de ciudadanos conformados por casas y vecindarios que viven en conjunto en busca del bien común, al ser este último la virtud, en el pensamiento tomista ${ }^{9}$.

Se puede encontrar inicialmente un análisis en el estudio preliminar de la obra por parte de Laureano Robles y Ángel Chueca, donde se exponen las influencias de Tomás de Aquino: "El pensamiento político de Tomás de Aquino está inspirado en Aristóteles y San Agustín. La síntesis de las dos forja su pensamiento e ideología" (Chueca y Robles, 1989, p. XXXV).

En continuación con lo anterior, es pertinente esta profundización en la relación entre los sistemas de organización social expuestos por Aristóteles y

\footnotetext{
${ }^{9}$ Véase Meyer, 1944.
} 
Agustín para poder entender el proceso que atraviesa el pensamiento tomista. Su postura ético-política recalca, entonces, dos líneas de pensamiento dominantes en su construcción de conceptos: "Aquino es primero un cristiano, y su aristotelismo es un aristotelismo cristiano [...] la vida política fue corrompida [...] y el Estado era una institución coercitiva diseñada para mantener un mínimo de orden en un mundo pecaminoso" (Sigmund, 1993, p. 218). Tomás de Aquino, toma gran parte de autores anteriores a él para intentar posicionarse como la síntesis de un nuevo pensamiento derivado de este estudio: "Desde una posición ontológica, Tomás de Aquino definió la res publica como la forma, mientras que el grupo de hombres representados en este contexto es la materia" (Marey, 2016, p. 170).

Esta noción de res publica es, entonces, un resultado de un complejo análisis de la historia de la filosofía hasta ese momento, por parte de Tomás de Aquino, y una reinterpretación de dichos postulados bajo la mirada del mismo aquinate que busca responder a la interpretación dominante de res publica de su época, momento de la historia en el cual se entendía desde una perspectiva diferente la idea de la res publica.

Al analizarse la forma en la que se entiende la res publica en la época de Tomás de Aquino es posible el pensar una articulación de la interpretación que él propone con otros elementos propios del Medioevo. Cuando se piensa en la metáfora corporatista ${ }^{10}$, que en aquella época se entendía como parte de lo que se conoce como metáfora política ${ }^{11}$, se hace referencia a que:

La res publica es un cuerpo (escribía John of Salisbury, uno de los grandes artífices de la difusión medieval de la metáfora «corporatista») y como partes de un cuerpo viviente deben ser entendidas las articulaciones institucionales de la comunidad política, cuya cabeza corresponde al príncipe, el corazón a sus consejeros, a los órganos de los sentidos los jueces, y así sucesivamente (Costa, 2007, p. 40).

Ambas nociones, metáfora corporatista y metáfora política, dan paso a construir una relación entre las líneas de pensamiento (Tomás y el resto del mundo Medieval) dando como resultado una visión de la res publica tomista complementada con la mirada de la metáfora corporatista, de modo que la teología aporte a la jerarquía que se construye en la metáfora de Juan de Salisbury. No obstante, no es solamente la metáfora política corporatista la que permite darle una nueva mirada a la noción tomista de res publica. También a través de la metáfora de la verticalidad viene corroborada la relación (analógica) entre la soberanía terrenal y la soberanía celeste, reforzando el carácter sagrado del poder.

\footnotetext{
${ }^{10}$ Véase Juan de Salisbury, 1984.

${ }^{11}$ Véase Briguglia, 1999.
} 
Al entrelazar los conceptos de Tomás de Aquino con los de la metáfora política corporativista $^{12}$ es válido analizar cómo la tradición política hasta ese momento siempre recurrió a esta metáfora con el cuerpo para referirse a la manera de ordenar la comunidad ${ }^{13}$. Esta comunidad articulada desde la metáfora corporatista y el pensamiento de Tomás de Aquino relaciona los conceptos de urbe, civitas, res publica y, finalmente, la civitas dei. En estos cuatro conceptos, bajo la mirada de la metáfora, se ubica la urbe, como el concepto que posee menor carácter de perfección divina, en el cuarto lugar. La civitas dei se sitúa en primer lugar como el último estadio que una organización humana puede alcanzar. Esto da paso a localizar en segundo lugar la civitas y en tercer lugar la res publica. Esta distinción entre el segundo y tercer puesto radica, como la metáfora misma, en que, si bien la civitas es una parte fundamental de la organización política, es la res publica, en calidad de ente político principal, la que articula todas las extremidades del cuerpo político.

La res publica, bajo la mirada expuesta, es un concepto que subordina las nociones de urb y civitas, de ahí la importancia de Tomás de Aquino de profundizar en el orden ético al que deben de estar dirigidas las normas en la organización política. La res publica se entiende, entonces, como un cuerpo ético-político articulado con distintas partes que lo constituyen para estar organizado de manera orgánica en una sola dirección, la cual es el goce divino, esto es, Dios. Este último, se ubica como sucesor de la res publica y, en ese orden de ideas, como todo lo que compone y organiza la res publica y, de la mano de la visión cristiana de mundo, permite la aproximación a la divinidad y a la vida plena en el otro mundo.

El resultado de procesar ambas perspectivas, la aristotélica y la agustiniana, lleva a Tomás de Aquino a relacionar los conceptos polis y res publica de forma similar, pero esto no se debe prestar para una lectura inmediata que lleve a suponer un simple matizar de conceptos (de un lado, Aristóteles con polis, y, por otro, Tomás de Aquino y res publica) donde se concluya, erróneamente, que ambos autores reducen su discurso respecto a sus conceptos de comunidades a ciudad o a Estado. Ahora bien, la pregunta sobre qué queda en el sistema filosófico de Aquino respecto a la organización política y social aristotélica de forma minuciosa y detallada prevalece; no es únicamente suponer una reinterpretación de conceptos, es tener conciencia de qué tanto hay del pensamiento de un autor en otro.

${ }^{12}$ Véase Rigotti, 1989.

${ }^{13}$ Véase Canning, 1980. 


\section{Un diálogo entre el concepto aristotélico de polis y la res publica tomista}

Es posible evidenciar una fuerte apropiación del pensamiento perteneciente a Aristóteles en múltiples de los postulados filosóficos de Tomás de Aquino y su obra; lo anterior, más que una hipótesis es una afirmación que se sustenta en toda la bibliografía a la cual se hizo referencia, literatura que, como es posible comprobar, demuestra de forma clara y concisa la manera en que Tomás de Aquino lee, piensa, contextualiza y recrea, a partir de su propio contexto, la obra aristotélica ${ }^{14}$.

Así dicho, el presente apartado se presenta como la síntesis de estas dos formas de reflexión, de modo que quede evidenciada la manera en la cual estas dos líneas de pensamiento forman en sí mismas una respuesta de un autor a otro, es decir, cómo Tomás de Aquino toma el pensamiento de Aristóteles, matiza los postulados con su contexto para producir nuevo conocimiento, tanto para la época en la que vive como para el aristotelismo ${ }^{15}$, de modo que quede, al menos en lo que respecta al concepto de res publica, claridad en la manera en que hay una correspondencia entre lo postulado por Aristóteles y lo retomado por Tomás de Aquino.

Ahora bien, al partir de lo escrito por Tomás Calvo, el aquinate se esforzó por presentar un sistema filosófico acorde con las creencias cristianas al asumir en dicho sistema conceptos fundamentales del aristotelismo dando fomento a la imagen aristotélica del universo ${ }^{16}$. De esta manera, se toma por acertado el decir que la res publica tiene una fuerte relación, por no decir que una influencia directa, con el trabajo expuesto por Aristóteles en sus escritos ético-políticos; en otras palabras, el concepto de res publica puede ser tomado como otro de esos conceptos que Tomás de Aquino estructura desde sus cimientos al partir del estagirita y su polis para ser matizado a partir de su contexto y constituir su teoría ético-política: "Para Tomás, no sólo la sociedad sino también el Estado [...] surgen de la naturaleza y no de una convención o de un contrato. Esto es precisamente lo que sostiene Aristóteles, al seguir a Platón contra los sofistas" (Cappelletti, 1987, p. 202).

Los postulados de Tomás de Aquino respecto a su pensamiento político igualmente se deslizan entre el de Agustín de Hipona y su propio contexto, pues algunos puntos de su teoría ético-política se vinculan fuertemente con el pensamiento agustiniano, aun sin dejar de lado siempre sus argumentos reforzados por el pensamiento aristotélico.

\footnotetext{
${ }^{14}$ Véase Grabmann, 1930.

${ }^{15}$ Véase Copleston, 1960.

${ }^{16}$ Véase Calvo, 2008.
}

Revista Filosofía UIS, vol. 19 n. ${ }^{\circ}$, enero - junio de 2020 
Así pues, se encuentra la diferencia principal entre estos dos conceptos. La forma en la que Tomás de Aquino aporta una finalidad por encima de la vida virtuosa, la consecución de Dios, es la diferencia entre su pensamiento y el de Aristóteles puesto que, con esta interpretación propia, articula al cuerpo político de la res publica con la búsqueda de dicho fin supremo dado por Dios para ser alcanzado por el hombre y así lograr la eternidad; distanciándose del estagirita, quien consideró la vida virtuosa como el fin último de la polis sin buscar una vida más allá de la muerte.

La forma en la que Tomás de Aquino estructura su pensamiento ético-político, a partir de la visión cristiana de mundo fundamentada en la obra de Aristóteles, le permite entrar en contacto con una apuesta para su época en relación con la forma en la cual se entendían las relaciones sociales entre distintos actores del cuerpo social y político de la res publica. El estagirita se vuelve, entonces, un filósofo al cual Tomás de Aquino se aproxima y se distancia de forma simultánea de manera que le sea posible una articulación apropiada del cristianismo con su contexto medieval al matizar las ideas de Aristóteles ${ }^{17}$; las diferencias existentes entre la doctrina tomista y el pensamiento de Aristóteles radican en los aportes del aquinate al pensamiento aristotélico desde la visión cristiana y desde el contexto del Medioevo, dándole a los conceptos aristotélicos un supra nivel en el cual Tomás de Aquino ubica a Dios, a la Trinidad y a la vida eterna del goce divino ${ }^{18}$.

Es posible, entonces, afirmar la secuencia que existe entre el pensamiento aristotélico, en relación con lo que respecta a la polis, con la forma en que Tomás de Aquino piensa la res publica, lo cual permite considerar el pensamiento tomista como un escaño en la jerarquía de pensamiento que se construye a lo largo de la historia de la filosofía, específicamente de la filosofía política, donde un autor retoma los fundamentos conceptuales de otro para aportar, desde su experiencia de época y de visión de mundo, a una tradición filosófica en particular: "En este sentido hay que tener en cuenta el modo en que las tesis aristotélicas están presentes en las obras de Santo Tomás. Se trata a veces de una presencia directa y a veces sólo de una presencia oblicua" (Belmonte, 2010, p. 277).

Con lo dicho se puede, entonces, afirmar la forma en la cual los dos conceptos se relacionan y se diferencian, esto es, la manera en la cual el concepto de res publica al contener en su sentido las bases aristotélicas posee las mismas características que la polis; no obstante, a la vez que posee este sentido, el concepto tomista tiene la capacidad de estar más allá de los límites presentes en el concepto de Aristóteles, esto último en parte por los cambios que corresponden a la época en la que cada autor vive, lo cual agota la interpretación del estagirita ${ }^{19}$

\footnotetext{
17 Véase Forment, 2010.

${ }^{18}$ Véase Hood, 2002.

${ }^{19}$ Véase Keys, 2006.
}

Revista Filosofía UIS, vol. 19 n. ${ }^{\circ}$, enero - junio de 2020 
y requiere un repensar sobre los conceptos que este último plantea para expandir los límites de la filosofía aristotélica más allá de lo dicho por el autor griego, lo cual permite al concepto del aquinate obtener el pensamiento aristotélico y ampliar sus límites al sentido que requiere el Medioevo ${ }^{20}$. Esto último lo logra, gracias al matizar derivado de la convergencia de filosofías distintas a la del estagirita.

\section{Conclusión}

Este artículo se fundamentó en la búsqueda de unos puntos en común y de distancia entre las propuestas ético-políticas, las cuales se encuentran contenidas en los conceptos de polis y de res publica de cada autor respectivamente, de modo que fuese posible dilucidar la forma en la que se constituye una macroestructura de pensamiento entre estos dos filósofos. Los tres acápites expuestos demuestran la manera en la cual esta macroestructura se construye entre estas dos etapas de la historia de la filosofía; se concluye que Tomás de Aquino es la síntesis medieval de un grupo de autores anteriores a él y con los cuales posee, aunque no en la misma medida que con Aristóteles, puntos en común que aportan a la teoría ético-política que él organiza.

Por un lado, Aristóteles se configura como la piedra angular en la visión de mundo tomista. Los postulados y conceptos del estagirita no solo complementan, sino que articulan y nutren de un sentido básico la forma tomista de ver el mundo, sin embargo, los demás pensadores, Cicerón y Agustín de Hipona especialmente, también forman parte de esta visión de mundo.

Por otro lado, Tomás de Aquino tiene una manera particular de formar su teoría ético-política. Para el aquinate la asimilación del pensamiento aristotélico a partir de una síntesis de pensamientos, al tener en cuenta la participación de otros autores secundarios, le permite una coyuntura filosófica que abre un espacio a un pensamiento propio. La manera adecuada de pensar su mundo es por medio de una síntesis del pensamiento anterior a él, siendo consciente de la historia que lo precede. Esto último, le permite pensar su realidad, su contexto histórico desde una mirada filosófica amplia y de panorama completo, se puede pensar a Tomás de Aquino como un historiador de la filosofía.

A modo de síntesis, las similitudes entre ambos autores son múltiples y recurrentes; el aristotelismo, tanto en lo ético-político como en otras dimensiones del pensamiento tomista, es evidente y no es negado por el aquinate, por el contrario, sus comentarios a las obras de Aristóteles refuerzan la influencia que este autor griego tuvo en su forma de entender la realidad por parte de Tomás de Aquino. Pero la mejor manera de remarcar dichas similitudes es al expresar las diferencias entre ambos pensadores, con lo cual se evidencia que el concepto

\footnotetext{
${ }^{20}$ Véase Martínez, 1992.
} 
de res publica busca constantemente una experiencia religiosa que se encuentra expresada en clave cristiana; es decir, para Tomás de Aquino todo el pensamiento aristotélico carece de algo, ese algo es la dimensión plena y realizativa de la vida en y con Dios.

La diferencia, a nivel general, entre Aristóteles y Tomás de Aquino se encuentra en la relación existente con lo divino, en el caso de Tomás de Aquino el Dios judeocristiano, y para Aristóteles el panteón griego, lo que da acceso a Tomás de Aquino a una mirada distinta a la perspectiva aristotélica, y aporta en la medida en que interpreta y cristianiza los conceptos y principios de Aristóteles; y es en ese punto, donde se separa de Aristóteles.

La distancia entre la res publica y la polis, a nivel especifico, radica, primero, en el fin último que se encuentra en las comunidades políticas, siendo la tomista poseedora de una amplitud mayor que la de Aristóteles; segundo, en la forma de gobierno perfecta, en este punto se encuentra en común que ambos autores alegan, de alguna manera, una mezcla de formas de gobierno, donde se encuentren las virtudes de los regímenes que ellos exponen; sin embargo, para Tomás de Aquino el sacerdocio y el papado juegan un papel en la gobernanza de la comunidad. Tercero, la res publica tomista responde a la Ley divina, que es la supervisora de la ley de la tierra y sin la cual no puede ser pensado el orden en la comunidad; finalmente, Tomás de Aquino encuentra en la Iglesia una reguladora constante de las relaciones entre los ciudadanos ${ }^{21}$, esta institución legitima la existencia de una comunidad tanto en lo ético como lo político.

Finalmente, las relaciones entre ambos autores se encuentran en la medida en que la polis de Aristóteles, con todos sus postulados y fundamentos, son el punto de partida para Tomás de Aquino, quien expande dichos principios y conceptos en la búsqueda de pensar su realidad. Así, la macroestructura que existe entre ambos autores se articula de forma directa, dando una dialéctica de tesis, antítesis y síntesis que permite la expansión de Aristóteles y el aristotelismo que se evidencia, en el caso de la perspectiva ético-política que se encuentra en la res publica, de manera innegable y constante en el pensamiento que postula Tomás.

\section{Referencias}

Agustín de Hipona (2010). La ciudad de Dios. (S. Santamarta y M. Fuertes, trads.). Madrid: Tecnos.

Aristóteles (1998). Ética Nicomáquea; Ética Eudemia. (J. Pallí Bonet, trad.). Madrid: Gredos.

${ }^{21}$ Véase Miethke, 1996. 
Aristóteles (1998). Política. (M. García Valdés, trad.). Madrid: Gredos.

Berti, E. (2012). El pensamiento político de Aristóteles. (H. Aguilà, trad.). Madrid: Gredos.

Belmonte, M. Á. (2010). La recepción de la prudencia política aristotélica en la síntesis de santo Tomás. En P. Roche (ed.), El pensamiento político en la Edad Media (pp. 275-286). Madrid: Centro de Estudios Ramón Areces.

Briguglia, G. (1999). 'Est respublica quoddam corpus'. Una metafora politica nel medioevo. Rivista di Storia della Filosofia, 54(4), 549-571.

Canning, J. (1980). The Corporation in the political thought of the italian jurists of the thirteenth and fourteenth centuries. History of Political Thought, 1(1), 9-32.

Cappelletti, Á. J. (1987). El aristotelismo político de Tomás de Aquino. Revista de Filosofía de la Universidad de Costa Rica, 25(62), 201-205.

Calvo, T. (2008). Aristóteles y el aristotelismo. Madrid: Akal.

Cicerón (1984). Sobre la república. (Á. D〉ors, trad.). Madrid: Gredos.

Copleston, F. (1960). El pensamiento de santo Tomás. (E. Frost, trad.). Ciudad de México: Fondo de Cultura Económica.

Costa, P. (2007). La soberanía en la cultura político-jurídica medieval: imágenes y teorías. Res publica: revista de filosofía política, (17), 33-58.

Chueca, Á. y Robles, L. (1989). Estudio preliminar. En Tomás de Aquino, La monarquía (pp. I-XLV). (L. Robles, trad.). Madrid: Tecnos.

Forment, E. (2010). Principios fundamentales de la filosofía política de Santo Tomás. En P. Roche (ed.), El pensamiento político en la Edad Media (pp. 93112). Madrid: Centro de Estudios Ramón Areces.

Gallego, J. (1996). Aristóteles, la ciudad-Estado y la Asamblea democrática. Reflexiones en tomo al libro III de la Política. Gerión, (14), 143-182.

Gallego, J. (2006). El inventario de las poleis del «Copenhagen Polis Centre» y la definición de la polis como ciudad y como estado. Ordia Prima, 5, 157-172.

Gallego, J. (2016). La Pólis griega: población, territorio y modelos políticos. Sociedades Precapitalistas, 6(1), 1-14. 
Goycoolea, R. (2005). Organización social y estructura urbana en las ciudades ideales de Platón y Aristóteles. A Parte Rei, (40), 1-13.

Grabmann, M. (1930). Santo Tomás de Aquino. (A. Salvador, trad.). Barcelona: Labor.

Hansen, M. (2006). Polis: an introduction to the ancient Greek city-state. New York: Oxford University Press.

Hodgson, L. (2017). Res publica and the Roman Republic 'Without Body or Form'. New York: Oxford University Press.

Hood, J. (2002). The essential Aquinas: writings on philosophy, religion and society. Connecticut: Praeger Publishers.

Keys, M. (2006). Aquinas, Aristotle, and the Promise of the Common Good. New York: Cambridge University Press.

Llanos, D. (2013). Política de Aristóteles y sus ciudades (in)finitas. Sapiens Research, $3(2), 24-28$.

Marey, A. (2016). From people to community: a description of the social order by Thomas Aquinas. Part 1: populus, respublica, multitudo. Russian Sociological Review, 15(4), 162-175.

Martínez, A. (1992). La concepción de la política en Santo Tomás. En Actas del I Congreso Nacional de Filosofía Medieval (pp. 381-388). Zaragoza: Sociedad de Filosofía Medieval.

Meyer, H. (1944). The philosophy of St. Thomas Aquinas. (F. Eckhoff, trad.). London: B. Herder Book Co.

Miethke, J. (1996). Las ideas políticas de la Edad Media. (F. Bertelloni, trad.). Buenos Aires: Biblos.

Platón (1999). Diálogos VII (Leyes I-VI). (F. Lisi, trad.). Madrid: Gredos.

Platón (1999). Diálogos IX (Leyes VII-XII). (F. Lisi, trad.). Madrid: Gredos.

Reeve, D. (2009). The naturalness of the polis in Aristotle. En G. Anagnostopoulos (ed.), A companion to Aristotle (pp. 512-525). Oxford: Wiley-Blackwell Publishing. 
Rigotti, F. (1989). Metafore della política. Bolognia: Il Mulino.

Sakellariou, M. (1989). The polis-state: definition and origin. (D. Hardy, trad.). Atenas: Diffusion de Boccard.

Salisbury, J. (1984). Policraticus. (M. Alcalá, F. Delgado, A. Echánove, M. García Gómez, A. López Caballero, J. Vargas y T. Zamarriego, trads.). Madrid: Editora Nacional.

Sánchez, D. (2016). Cicerón y Agustín. A propósito de la república. Universitas Philosophica, 33(67), 217-238.

Sellers, M. (2009). The Influence on Marcus Tullius Cicero on modern legal and political ideas. Ciceroniana, 9, 245-280.

Sigmund, P. (1993). Law and Politics. En N. Kretzmann y E. Stump (eds.), The Cambridge companion to Aquinas (pp. 217-231). New York: Cambridge University Press.

Tomás de Aquino (1988). Suma de teología II. (Regentes de Estudios de las Provincias Dominicanas en España, trads.). Madrid: Biblioteca de Autores Cristianos.

Tomás de Aquino (1989). La monarquía. (L. Robles \& A. Chueca, trads.). Madrid: Tecnos.

Tomás de Aquino (2010). Comentario a la Ética de Aristóteles. (A. Mallea, trad.). Navarra: Universidad de Navarra.

Tomás de Aquino (2012). La monarquía, al rey de Chipre. En Tomás de Aquino, Textos selectos (pp. 699-687). (L. Robles, trad.). Madrid: Gredos.

Tomás de Aquino y Pedro de Alvernia (2001). Comentario a la Política de Aristóteles. (A. Mallea, trad.). Navarra: Universidad de Navarra.

Thomas, R. (2002). La ciudad clásica. En R. Osborne (ed.), La Grecia Clásica: 500323 a. C. (pp. 63-94). (G. Djembé, trad.). Barcelona: Editorial Crítica.

Woldring, H. (1999). On the purpose of the state: continuity and change in political Theories. En B. Sweetman (ed.), The failure of modernism: the cartesian legacy and contemporary pluralism (pp. 155-170). Washington D. C.: The Catholic University of America Press. 